
\title{
25 Research Suare \\ Dynamic APACHE II Score to Predict Outcome Among Intensive Care Unit Patients
}

\section{Yao Tian}

The first affiliated hospital of Xi'an medical university

\section{Yang YAO}

First Affiliated Hospital of Xi'an Medical University https://orcid.org/0000-0002-5437-1558

\section{Jing Zhou}

The first affiliated hospital of Xi'an medical university

\section{Xin Diao}

The first affiliated hospital of Xi'an medical university

\section{Hui Chen}

The first affiliated hospital of Xi'an medical university

\section{Kaixia Cai}

The first affiliated hospital of Xi'an medical university

\section{Xuan Ma}

The first affiliatedh hospital of Xi'an medical university

Shengyu Wang ( $\nabla$ wangshengyu@yeah.net)

The first affiliatedh hospital of Xi'an medical university

\section{Research}

Keywords: APACHE II, Mortality, Intensive care units, MIMIC-III, Predictor

Posted Date: June 28th, 2021

DOl: https://doi.org/10.21203/rs.3.rs-642050/v1

License: (c) (1) This work is licensed under a Creative Commons Attribution 4.0 International License. Read Full License 


\section{Abstract}

Purpose: The Acute Physiology and Chronic Health Evaluation II (APACHE II) score is used to determine disease severity and predict outcomes in critically ill patients. However, there is no dynamic APACHE II score for predicting outcomes among ICU patients. The aim of this study is to explore the optimal timing to predict the outcomes of ICU patients by dynamically evaluating APACHE II score.

Methods: Study data of demographics and comorbidities from the first $24 \mathrm{~h}$ after ICU admission were retrospectively extracted from MIMIC-III, a multiparameter intensive care database. The primary outcome was hospital mortality. 90-day mortality was a secondary outcome. APACHE II scores on days 1, 2, 3, 5, 7, 14 and 28 were compared using area under the receiver operating characteristic (AUROC) analysis. Hospital survival was visualised using Kaplan-Meier Curves.

Results:A total of 6374 eligible subjects were extracted from the MIMIC-III. Mean APACHE II score on day 1 were $18.4 \pm 6.3$, hospital and 90 -day mortality was $19.1 \%$ and $25.8 \%$, respectively. The optimal timing where predicted hospital mortality was on day 3 with an area under the cure of $0.666(0.607-0.726)(P]$ $0.0001)$. The best tradeoff for preciction was found at 17 score, more than 17 score predicted mortality of non-survivors with a sensitivity of $92.8 \%$ and PPV of $23.1 \%$. Hosmer-lemeshow goodness of fit test showed that APACHE II 3 has a good predictive calibration ability $\left(X^{2}=6.198, P=0.625\right)$ and consistency of predicted death and actual death was $79.4 \%$. The calibration of APACHE II 1 was poor $\left(X^{2}=294.898\right.$, $P<0.001)$.

Conclusions: APACHE II on 3 dayis the optimal prognostic marker and 17 score provided the best dignostic accuracy to predict outcomes for ICU patients. These finding will help medical make clinical judgment.

\section{Introduction}

Predicting ICU mortality plays an important role in patient care and resource allocation, Early identification and management are associated with lower mortality[1, 2]. At present, there are many predictive scoring systems including Acute Physiology Chronic Health Evaluation II (APACHE II), Organ Dysfunction and Infection System, Sequential Organ Failure Assessment (SOFA) and Simplified Acute Physiology Score (SAPS) for hospital outcomes[3-5], especially for mortality [6, 7], Among which APACHE II score is the most common and well-known effective prediction scoring method. At present, most studies use the APACHE II score within $24 \mathrm{~h}$ of admission to predict the outcomes of patients[2, 8], However, for the first $24 \mathrm{~h}$ of ICU admission, many patients have several comorbid conditions, and selecting only one principal diagnostic category may be very difficult, Moreover, the condition of patients was unstable and their physiological indexes fluctuated greatly, All these factors had a great impact on APACHE II score within $24 \mathrm{~h}$, which leads to inaccurate prognosis of hospital outcomes. In addition, Evaluation criteria are usually based on the area under receiver operating characteristic (ROC) curve, which may not be enough to guide the decision on which model is the best. Good of fit testing is another 
factor that should be considered. Therefore, it is very significance to explore the optimal timing for APACHE $₫$ score by dynamically evaluating the APECHE II score and verify its calibration.

\section{Methods}

\section{Date source}

This study based on Medical Information Mart for Intensive Care (MIMIC) III (Philips Healthcare, Andover, MA; and Beth Israel Deaconess Medical Center) ICU database, which is large, publicly available database compromising the clinical diagnosis and treatment information of approximately 46,000 critically ill patients admited to the Beth Israel Deaconess Medical Center (Boston, Massachusetts) from 2001 to 2012[9-11]. We obtained approval to access the database(Certification Number: 36379199) after completing the National Institutes of Health web-based training course“Protecting Human Research Participants".

\section{Date Extraction And Management}

Two authors independently extracted the relevant date and assessed the eligibility and quality of the study. Date on the following aspects were extracted: age, sex, survival status, admission type, date of ICU and hospital admission and discharge, date of birth and death. The hospital and ICU length of stay (LOS), Patients discharged from hospital or deceased before day 28 were censored to the last known APACHE II score. APACHE II scores was calculated as described in previous studies[12, 13], The days of hospitalization were calculated by subtracting the time of admission from the time of discharge. To safeguard patient privacy, date were deidentified[14], therefore, The days of death after discharge were calculated by subtracting the date of discharge from the date of death of each patient, and the 90-day mortality was further calculated. Only the first diagnosis was selected as the object of date analysis, and the disease classification was gradually refined according to the International Classification of Diseases9th (ICD-9) edition comorbidities[15], Serial APACHE II scores were calculated on days 1,2,3,5,7,14 and 28 after enrollment in ICU. The primary endpoint was hospital mortality. The secondary endpoints was 90 day mortality, For patients younger (>18 year old) readmitted to the ICU, only the first ICU admissions were included. Date were extracted from the following tables(ADMISSIONS,ICUSTAYS, PATIENTS, CHARTEVENTS, LABARARY EVENTS and DIAGNOSIS_ICD). We excluded patients who were Individuals were exclued if (1)stayed in ICU less than on day; (2) Patients with missing date of APECH II score.

\section{Statistical analysis}

Quantitative variables and categorical date are expressed as mean \pm SD and (number and percentage),respectively. Compared between groups using a t-test, if the data were normally distribted and the variance was homogeneous. If not, data were represented by the median and interquaritile range, and the wilcoxon rank-sum test was used for comparisons between groups.Discrimination and 
calibration were assessed using the area under the receiver operating characteristics curve (AUROC) and Hosemer-Lemeshow statistic, respectively. We used the Youden Index to estimate the optimal cut off values by finding values that returned the maximum specificity and sensitivity. $P \otimes 0.05$ was considered statistically significant. Statistical analysis was performed by IBM SPSS Statistics (IBM, Armonk, NY, USA).

\section{Results}

\section{Baseline patient characteristics and outcomes}

The flow charts is shown in Fig. 1. A total of 46520 patients were including in MIMIC-III database. After including only patients' first ICU admissions and exclueding admissions under the age of 18, less than 24 $\mathrm{h}$ in ICU and lack of Apache II scords, Finally, 6374 patients were included in this study (Fig. 1). The baseline characteristics and outcomes of patients are summarized in Table 1. The overall mean age was $64.1 \pm 16.8$ years $(63.2 \pm 16.7$ in survivors Vs $68.4 \pm 15.9$ in non-survivors), $57.8 \%$ was male $(n=3683)$, The difference of demographics between survivors and non-survivors were statistically significant (Pख0.05). APACHE II on days 1, 2, 3, 5, 7, 14 and 28 were 18.4 $\pm 6.3,15.4 \pm 5.8,15.9 \pm 5.9,16.8 \pm 5.8,17.5 \pm$ $6.3,17.6 \pm 6.6$ and $15.7 \pm 6.9$, respectively. The non-survivor group showed higher APACHE II score compared to survivor group at all test points $(P<0.001)$. The hospital mortality and ICU mortality were $19.1 \%$ and $15.7 \%$, respectively, ICU and hospital LOS (Length of stay) were $8.62 \pm 9.0$ and $15.7 \pm 13.7$ days. Besides, the diseases of circulatory system was listed as the most common diagnosis among 1865 patients (29.3\%). 
Table 1

Comparative baseline demographics according to survival status

\begin{tabular}{|c|c|c|c|c|}
\hline Variables & $\begin{array}{l}\text { All } \\
(n=6374)\end{array}$ & $\begin{array}{l}\text { Survivors } \\
(n=5158)\end{array}$ & $\begin{array}{l}\text { Nonsurvivors } \\
(n=1216)\end{array}$ & $\begin{array}{l}P \\
\text { values }\end{array}$ \\
\hline \multicolumn{5}{|l|}{ Demographics } \\
\hline Age, mean (SD), year & $64.1 \pm 16.8$ & $63.2 \pm 16.7$ & $68.4 \pm 15.9$ & $\begin{array}{l}P< \\
0.001\end{array}$ \\
\hline Male, No. (\%) & $3683(57.8)$ & $3019(58.5)$ & $664(54.6)$ & $\begin{array}{l}P= \\
0.013\end{array}$ \\
\hline \multicolumn{5}{|l|}{ APACHII score(SD) } \\
\hline APACHII on day 1 & $18.4 \pm 6.3$ & $18.0 \pm 6.3$ & $19.8 \pm 6.1$ & $\begin{array}{l}P< \\
0.001\end{array}$ \\
\hline APACHII on day 2 & $15.4 \pm 5.8$ & $14.5 \pm 5.4$ & $19.6 \pm 5.7$ & $\begin{array}{l}P< \\
0.001\end{array}$ \\
\hline APACHII on day 3 & $15.9 \pm 5.9$ & $14.5 \pm 5.2$ & $20.2 \pm 5.8$ & $\begin{array}{l}P< \\
0.001\end{array}$ \\
\hline APACHII on day 5 & $16.8 \pm 5.8$ & $14.9 \pm 4.9$ & $20.6 \pm 5.7$ & $\begin{array}{l}P< \\
0.001\end{array}$ \\
\hline APACHII on day 7 & $17.5 \pm 6.3$ & $15.0 \pm 5.1$ & $21.6 \pm 5.9$ & $\begin{array}{l}P< \\
0.001\end{array}$ \\
\hline APACHII on day 14 & $17.6 \pm 6.6$ & $14.2 \pm 4.8$ & $22.4 \pm 5.8$ & $\begin{array}{l}P< \\
0.001\end{array}$ \\
\hline APACHII on day 28 & $15.7 \pm 6.9$ & $12.4 \pm 4.4$ & $23.2 \pm 5.6$ & $\begin{array}{l}P< \\
0.001\end{array}$ \\
\hline \multicolumn{5}{|l|}{ Outcomes } \\
\hline Hospital mortality, №. (\%) & 1216(19.1) & 0 & $1216(100)$ & $\begin{array}{l}P< \\
0.001\end{array}$ \\
\hline ICU mortality, No. (\%) & $1001(15.7)$ & 0 & $1001(82.3)$ & $\begin{array}{l}P< \\
0.001\end{array}$ \\
\hline 90-day mortality, No. (\%) & $\begin{array}{l}1648 \\
(25.8)\end{array}$ & 0 & $1648(25.8)$ & $\begin{array}{l}P< \\
0.001\end{array}$ \\
\hline ICU LOS, median (IQR), d & $8.62 \pm 9.0$ & $8.5 \pm 9.1$ & $9.3 \pm 8.9$ & $\begin{array}{l}P= \\
0.005\end{array}$ \\
\hline Hospital LOS, median (IQR), d & $15.7 \pm 13.7$ & $16.4 \pm 13.8$ & $12.6 \pm 12.8$ & $\begin{array}{l}P< \\
0.001\end{array}$ \\
\hline
\end{tabular}




\begin{tabular}{|c|c|c|c|c|}
\hline Variables & $\begin{array}{l}\text { All } \\
(n=6374)\end{array}$ & $\begin{array}{l}\text { Survivors } \\
(n=5158)\end{array}$ & $\begin{array}{l}\text { Nonsurvivors } \\
(n=1216)\end{array}$ & $\begin{array}{l}P \\
\text { values }\end{array}$ \\
\hline Infectious and parasitic diseases & 619(9.7) & $422(8.2)$ & 197(16.2) & $\begin{array}{l}P< \\
0.01\end{array}$ \\
\hline Neoplasms & $180(2.8)$ & $135(2.6)$ & $45(3.7)$ & $\begin{array}{l}P< \\
0.01\end{array}$ \\
\hline $\begin{array}{l}\text { Endocrine,nutritional,and metabolic disease } \\
\text { and immunity disorders }\end{array}$ & $642(10.1)$ & $560(10.9)$ & $82(6.7)$ & $\begin{array}{l}P< \\
0.01\end{array}$ \\
\hline Blood and Blood forming organs & $568(8.9)$ & $488(9.5)$ & $80(6.6)$ & $\begin{array}{l}P< \\
0.01\end{array}$ \\
\hline $\begin{array}{l}\text { Diseases of nervous system and sense } \\
\text { organs }\end{array}$ & $69(1.1)$ & $65(1.3)$ & $4(0.33)$ & $\begin{array}{l}P< \\
0.01\end{array}$ \\
\hline Diseases of circulatory system & 1865(29.3) & 1579(30.6) & $277(22.8)$ & $\begin{array}{l}P< \\
0.01\end{array}$ \\
\hline Diseases of respiratory system & $982(15.4)$ & $765(14.8)$ & $217(17.8)$ & $\begin{array}{l}P< \\
0.01\end{array}$ \\
\hline Diseases of digestive system & $445(6.9)$ & $369(7.2)$ & $76(6.3)$ & $\begin{array}{l}P< \\
0.01\end{array}$ \\
\hline Diseases of genitourinary system & $657(10.3)$ & $463(8.9)$ & 194(16.0) & $\begin{array}{l}P< \\
0.01\end{array}$ \\
\hline Disease skin and subcutaneous tissue & $82(1.3)$ & $67(1.3)$ & $15(1.2)$ & $\begin{array}{l}P< \\
0.01\end{array}$ \\
\hline $\begin{array}{l}\text { Diseases of musculoskeletal } \\
\text { and connective tissue }\end{array}$ & $40(0.6)$ & $36(0.7)$ & $4(0.3)$ & $\begin{array}{l}P< \\
0.01\end{array}$ \\
\hline Injury and poisoning & $234(3.7)$ & $209(4.1)$ & $25(2.1)$ & $\begin{array}{l}P< \\
0.01\end{array}$ \\
\hline
\end{tabular}


Table 2

Prognostic performance for outcomes of the 17 cutoff on Apechll 3 day

\begin{tabular}{|llllll|}
\hline APACHII score & Hospital mortality & \multicolumn{3}{l|}{ 90-day mortality } & \\
\cline { 2 - 6 } & Non-survivors (n) & Survivors(n) & Non-survivors (n) & Survivors(n) & Total \\
\hline APACHII $\geq 17$ & 928 & 3081 & 1213 & 2796 & 4009 \\
\hline & Sens:92.8\% & Sens:82.2\% & Sens:92.2\% & Sens:81.3\% \\
\hline APACHI $<17$ & PPV: $23.1 \%$ & & PPV:30.3\% & \\
\hline & Spec:90.1\% & Spec:80.2\% & Spec: $100 \%$ & Spec:80.2\% \\
\hline
\end{tabular}


Table 3

The Hosmer-lemeshow goodness of fit test

\begin{tabular}{|c|c|c|c|c|c|}
\hline \multirow{2}{*}{$\begin{array}{l}\text { Declie of Risk } \\
\text { Hospitalmortality }\end{array}$} & \multicolumn{2}{|l|}{ Survival } & \multicolumn{2}{|c|}{ Non-survival } & \multirow[t]{2}{*}{ Total } \\
\hline & Observed & Expected & Observed & Expected & \\
\hline \multicolumn{6}{|c|}{ The Hosmer-lemeshow goodness of fit test of Apechll 3 day } \\
\hline 1 & 341 & 341.392 & 14 & 13.608 & 355 \\
\hline 2 & 327 & 330.766 & 28 & 24.234 & 355 \\
\hline 3 & 329 & 321.526 & 26 & 33.474 & 355 \\
\hline 4 & 318 & 311.866 & 37 & 43.134 & 355 \\
\hline 5 & 302 & 299.902 & 53 & 55.098 & 355 \\
\hline 6 & 275 & 284.631 & 80 & 70.369 & 355 \\
\hline 7 & 269 & 266.116 & 86 & 88.884 & 355 \\
\hline 8 & 239 & 244.417 & 116 & 110.583 & 355 \\
\hline 9 & 207 & 211.180 & 148 & 143.820 & 355 \\
\hline 10 & 148 & 143.203 & 206 & 210.797 & 354 \\
\hline \multicolumn{6}{|c|}{ The Hosmer-lemeshow goodness of fit test of Apechll 1day } \\
\hline 1 & 565 & 581.870 & 65 & 48.130 & 630 \\
\hline 2 & 562 & 561.981 & 68 & 68.019 & 630 \\
\hline 3 & 563 & 548.176 & 65 & 81.824 & 630 \\
\hline 4 & 534 & 535.885 & 96 & 94.115 & 630 \\
\hline 5 & 542 & 524.260 & 88 & 105.740 & 630 \\
\hline 6 & 519 & 512.451 & 111 & 117.549 & 630 \\
\hline 7 & 517 & 499.186 & 113 & 130.814 & 630 \\
\hline 8 & 488 & 483.031 & 142 & 146.969 & 630 \\
\hline 9 & 426 & 458.489 & 204 & 171.511 & 630 \\
\hline 10 & 382 & 394.670 & 251 & 238.330 & 633 \\
\hline
\end{tabular}

The predictive value of dynamic APACHE II score for hospital mortality

Analysis of discrimination of APACHE II score on day 1,2,3,5,7,14 and 28 for predicting hospital mortality using ROC curves are shown in Fig. 2, The earliest time point when the achieved AUROC was greater than previous days was on day $3(P<0.001)$. (APACHE II 1: 0.579 [95\%Cl:0.516-0.642], APACHE II 2: 0.587 
[95\%Cl:0.524-0.650], APACHE II 3: 0.666 [0.607-0.726], APACHE II 5: 0.695 [0.636-0.755], APACHE II 7: 0.701 [0.643-0.759], APACHE II 14: 0.807 [0.759-0.854] and APACHE II 28: 0.934[0.909-0.959]).

Comparing the area under the ROC curve with the histogram, it is found that the area under the ROC curve on the third day is the earliest time point than the previous days to predict hospital mortality $(P=0.024)$ (Fig. 2b). To this end, Our subsequent analysis focuses on the development of APACHE II 3 as an optimal predictor of hospital mortality.

The third day Youden index was used to analyze the survival and non-survival group showed that in the APACHE II $\geq 17$ group, 928(23.1\%) patients were in the non-survival group, the sensitivity was $92.8 \%$, PPV was $23.1 \%, 3081$ patients ( $82.2 \%$ ) were in the survival group, the sensitivity was $82.2 \%$. In the group of APACHE II less than 17, 288 patients were non survival, the specificity was $90.1 \%, 2077$ patients were survival, the specificity was $80.2 \%$, NPV was $87.8 \%$ (Table.2). In the Kaplan-Meier survival curves, APACHE II less than 17 had higher survival rate(Pख0.0001)(Fig. 3).

\section{The predictive value of dynamic APACHE II score for 90-day mortality}

The APACHE II 3 day ROC curve for predicting 90-day mortality was 0.743 ( $95 \% \mathrm{Cl}: 0.729-0.756$, $P \otimes 0.001)$, Youden index of 17 was used to analysis of 90 day survival status, indicated that in the group of APACHE II less than 17, 435 patients were non survival, the specificity was $100 \%, 1930$ patients were survival, the specificity was $80.2 \%$, NPV was $81.6 \%$.(Table.2)

\section{Score Calibration}

The results of Hosmer-lemeshow goodness of fit test of APACHE II 3 day showed that there was no statistical difference between the predicted value and the actual value $\left(\mathrm{X}^{2}=6.198, P=0.625\right)$, indicating that the model has a good predictive calibration ability(Table.3). The consistency of predicted death and actual death was $79.4 \%$. For APACHE II on 1 day, the calibration is poor $\left(X^{2}=294.898, P<0.001\right)$ (Table.3).

\section{Discussion}

This is the first article on the relationship between dynamic APACHE II score and outcomes of ICU patients, and found that APACHE II score on the third day was the optimal predictor of outcomes in ICU patients.

Many studies have confirmed that APACHE II score is a useful prognostic marker of mortality. A retrospective study of 200 Iranian patients admitted in ICU reported that an APACHE II score of 15 provides the best diagnositic accuracy to predict mortality of critically ill patients[6].Liu J have shown that initial APACHE II scores on day of ICU admission and correlated with survival outcomes[16]. A study included 109 cirrhotic MICU patients reported that APACHE II can be a predictor of mortality[17]. This help in categorizing patients and to facilitate early risk identification. These studies used APACHE II scores within $24 \mathrm{~h}$ after admission, although early identification of mortality helps to classify patients and early 
identify risks. However, many factors affecting the prognosis of ICU patients within $24 \mathrm{~h}$ were ignored. This study founded that the APACHE II scores on the first day have poorly calibration on hospital mortality. This results is consistent with that of Kim[8], They founded that in the analysis of 826 Koreans patients, the APACHE II from the first $24 \mathrm{~h}$ after admission to the ICU exhibits poor calibration for hospital mortality. In large representative study of $141,106 \mathrm{ICU}$ patients in the UK also confirmed that APACHE II showed good discrimination but imperfect calibration for hospital mortality[18]. Therefore, a new model is needed to accuratey predict mortality in ICU patients. In recent years, although many new models have been developed to predict the mortality of ICU patients[19], there new models still need to be verified by multi-center and large sample studies. APACHE II score is still a high acceptance score, therefore, it is more meaningful and popular to find an effective score based on APACHE II score to predict outcomes of ICU patients.

Just as the accuracy of dynamic SOFA score in predicting sepsis is higher than that of SOFA score[7, 20, 21]. Some scholars suggest that the APACHE II score should be proposed during the initial 7 days of ICU stay to reduce the error to the greatest extent[22]. However, due to the complexity of APACHE II score, daily assessment will bring huge workload, so it is more valuable to find out the optimal time to predict outcome of ICU patienst. In this study, Serial APACHE II scores were calculated on day 1, 2, 3, 5, 7, 14 and 28 after admission to ICU, and found that APACHE II scores on day 3 is a useful predictor of hospital and 90-day mortality in ICU patients.

Bahtouee' study have reported that APACHE II with a score of 15 gave the best diagnostic accuracy to predict ICU mortality[6]. In a study by Hosseini et al and Fadaizadeh et al reported the best cut-off point chosen was 13.5 in APACHE II score predicted hospital mortality, These result is lower than the 17 points we got in this study. This difference may be related to the following factors: First, Based on the date from the first $24 \mathrm{~h}$ after admision to ICU[23, 24].There maybe ignore influenced factors as recent and ongoing resuscitation and therapy. Second, The sample size of the previous study is small, and this study uses a larger sample size, so we can draw a more reliable conclusion. Third, The 17 score of this study were obtained from the third day of APACHE II, while the previous study was the first, so different conclusions were drawn.

There are still limitations in this study. Firstly, this study is a retrospective study, but all the necessary data have been colledcted, so it limits the possible bias of this method. Second, all the date are from the MIMIC-III (2001-2012), the results may not reflect current practices, Besides, most of pateint included in MIMIC-III are from North American ICUs who descended from different populations. Third, our study only included date availavle online and more external validation is still required.

\section{Conclusion}

We explored the correlation between APACHE II score and outcomes of ICU patients, and found that APACHE II score on the third day was the optimal time to predict outcomes in ICU patients. These finding will help medical make clinical judgment and sound clinical sense. 


\section{Abbreviations}

APACHE II

The Acute Physiology and Chronic Health Evaluation II; AUROC:Area under the receiver operating characteristic; SOFA:Sequential Organ Failure Assessment; SAPS:Simplified Acute Physiology Score; MIMIC:Medical Information Mart for Intensive Care; LOS:length of stay; ICD-9:International Classification of Diseases-9th

\section{Declarations}

\section{Author details}

All authors are from Department of Pulmonary and Critical Care Medicine, The First Affiliated Hospital of Xi'an Medical University, Xi'an, Shaanxi, 710077, PR China

\section{Acknowledgments}

We would like to thank MIT for providing a large amount of valuable data on critically ill patients. We are grateful to Yanfei Shen for providing help in using the MIMIC database.

\section{Author contributions}

YT and YY contributed to the initial study concept and design. SYW obtained funding for the study. JZ, $X D$ and $\mathrm{HC}$ contributes to the final study design. YT, YY and SYW participated in the first drafting of the manuscript. YT and YY perform data collectoin, and date analysis. KXC and XM contributed in comment on the manuscript and statistical analysis. All authors participated in the critical revision for intellectual content, and read and approved the fnal manuscript.

\section{Funding}

This project was supported by funds from the Seventh Batch of Science and Technology Planning Projects in Xi'an (20YXYJ0001[07])

\section{Compliance with ethical standards}

There are no conflicts of interest to disclose.

\section{Ethical approval}

The data of this study are from MIMIC-III database, and do not involve ethical approval.

\section{Consent to participate}

The data of this study are from MIMIC-III database, Consent to participate are not applicable. 


\section{Availiability of data and materials}

All data needed to evaluate the conclusions of this article are present and tabulated in the main text or in the ESM. For individual de-identifed raw data that underlie the results reported in this article, please contact the corresponding author after publication.

\section{Author details}

All authors are from Department of Pulmonary and Critical Care Medicine, The First Affiliated Hospital of Xi'an Medical University, Xi'an, Shaanxi, 710077, PR China

\section{References}

1. Goulden R, Hoyle MC, Monis J, Railton D, Riley V, Martin P, et al. qSOFA, SIRS and NEWS for predicting inhospital mortality and ICU admission in emergency admissions treated as sepsis. Emerg Med J. 2018;35:345-9.

2. Zou X, Li S, Fang M, Hu M, Bian Y, Ling J,et al. Acute Physiology and Chronic Health Evaluation II Score as a Predictor of Hospital Mortality in Patients of Coronavirus Disease 2019. Crit Care Med. 2020;48:e657-65.

3. Raith EP, Udy AA, Bailey M, McGloughlin S, Maclsaac C, Bellomo R, et al. Prognostic Accuracy of the SOFA Score, SIRS Criteria, and qSOFA Score for In-Hospital Mortality Among Adults With Suspected Infection Admitted to the Intensive Care Unit. JAMA. 2017;317:290-300.

4. Lambden S, Laterre PF, Levy MM, Francois B. The SOFA score-development, utility and challenges of accurate assessment in clinical trials. Crit Care. 2019;23:374.

5. Bjorck V, Pahlman LI, Bodelsson M, Petersson AC. Kander.Morbidity and mortality in critically ill patients with invasive group A streptococcus infection: an observational study. Crit Care. 2020;24:302.

6. Bahtouee M, Eghbali SS, Maleki N, Rastgou V, Motamed NAcute. Physiology and Chronic Health Evaluation II score for the assessment of mortality prediction in the intensive care unit: a singlecentre study from Iran. Nurs Crit Care. 2019;24:375-80.

7. de Grooth HJ, Geenen IL, Girbes AR, Vincent JL, Parienti JJ, Oudemans-van Straaten HM. SOFA and mortality endpoints in randomized controlled trials: a systematic review and meta-regression analysis. Crit Care. 2017;21:38.

8. Kim JY, Lim SY, Jeon K, Koh Y, Lim CM, Koh SOmet. al. External validation of the Acute Physiology and Chronic Health Evaluation II in Korean intensive care units. Yonsei Med J. 2013;54:425-31.

9. Chen H, Zhu Z, Zhao C, Guo Y, Chen D, Wei Y, et al. Central venous pressure measurement is associated with improved outcomes in septic patients: an analysis of the MIMIC-III database. Critical care (London, England). 2020; 24:433.

10. Feng M, McSparron JI, Kien DT, Stone DJ, Roberts DH, Schwartzstein RM, et al. Transthoracic echocardiography and mortality in sepsis: analysis of the MIMIC-III database. Intensive care med. 
2018;4:884-92.

11. Lee J, Ribey E, Wallace JR. A web-based data visualization tool for the MIMIC-II database. BMC Med Inform Decis Mak. 2016;16:15.

12. Lee H, Lim CW, Hong HP, Ju JW, Jeon YT, Hwang JW, et al. Efficacy of the APACHE II score at ICU discharge in predicting post-ICU mortality and ICU readmission in critically ill surgical patients. Anaesthesia intensive care. 2015;43(2):175-86.

13. Whitehouse T, Hodson J, Pemberton P, Veenith T, Snelson C, Bion J, et al. The Association Between Visiting Intensivists and ICU Outcomes. Crit Care Med. 2017;45:949-55.

14. Cheng B, Li D, Gong Y, Ying B, Wang BSerum. Anion Gap Predicts All-Cause Mortality in Critically III Patients with Acute Kidney Injury: Analysis of the MIMIC-III Database. Dis Markers. 2020;2020:6501272.

15. Ye W, Chen X, Huang Y, Li Y, Xu Y, Liang Z, et al. The association between neutrophil-to-lymphocyte count ratio and mortality in septic patients: a retrospective analysis of the MIMIC-III database. J Thorac Dis. 2020;12:1843-55.

16. Liu J, Cheng Q, Yang Q, Li X, Shen X, Zhang L, et al. Prognosis-related factors in intensive care unit (ICU) patients with hematological malignancies: A retrospective cohort analysis in a Chinese population. Hematology. 2015;20:494-503.

17. Elzouki AN, Suliman S, Alhasan R, Abdullah A, Othman M, Badi A. Predicting mortality of patients with cirrhosis admitted to medical intensive care unit: An experience of a single tertiary center. Arab $\mathrm{J}$ Gastroenterol. 2016;17:159-63.

18. Harrison DA, Brady AR, Parry GJ, Carpenter JR, Rowan K. Recalibration of risk prediction models in a large multicenter cohort of admissions to adult, general critical care units in the United Kingdom. Crit Care Med. 2006;34:1378-88.

19. Fika S, Nanas S, Baltopoulos G, Charitidou E, Myrianthefs P. A novel mortality prediction model for the current population in an adult intensive care unit. Heart lung. 2018;47:10-5.

20. Karakike E, Kyriazopoulou E, Tsangaris I, Routsi C, Vincent JL, Giamarellos-Bourboulis EJ. The early change of SOFA score as a prognostic marker of 28-day sepsis mortality: analysis through a derivation and a validation cohort. Crit Care (London England). 2019;23:387.

21. Ju XF, Wang F, Wang L, Wu X, Jiang TT, You DL, et al. Dynamic Change of Red Cell Distribution Width Levels in Prediction of Hospital Mortality in Chinese Elderly Patients with Septic Shock. Chin Med J (Engl). 2017;130:1189-95.

22. Wagner DP, Knaus WA, Harrell FE, Zimmerman JE, Watts C. Daily prognostic estimates for critically ill adults in intensive care units: results from a prospective, multicenter, inception cohort analysis. Crit Care Med. 1994;22:1359-72.

23. Hosseini M, Ramazani J. Comparison of acute physiology and chronic health evaluation II and Glasgow Coma Score in predicting the outcomes of Post Anesthesia Care Unit's patients. Saudi J Anaesth. 2015;9:136-41. 
24. Haq A, Patil S, Parcells AL, Chamberlain RS. The Simplified Acute Physiology Score III Is Superior to the Simplified Acute Physiology Score II and Acute Physiology and Chronic Health Evaluation II in Predicting Surgical and ICU Mortality in the "Oldest Old". Curr Gerontol Geriatr Res. 2014;2014:934852.

\section{Figures}

Fig.1

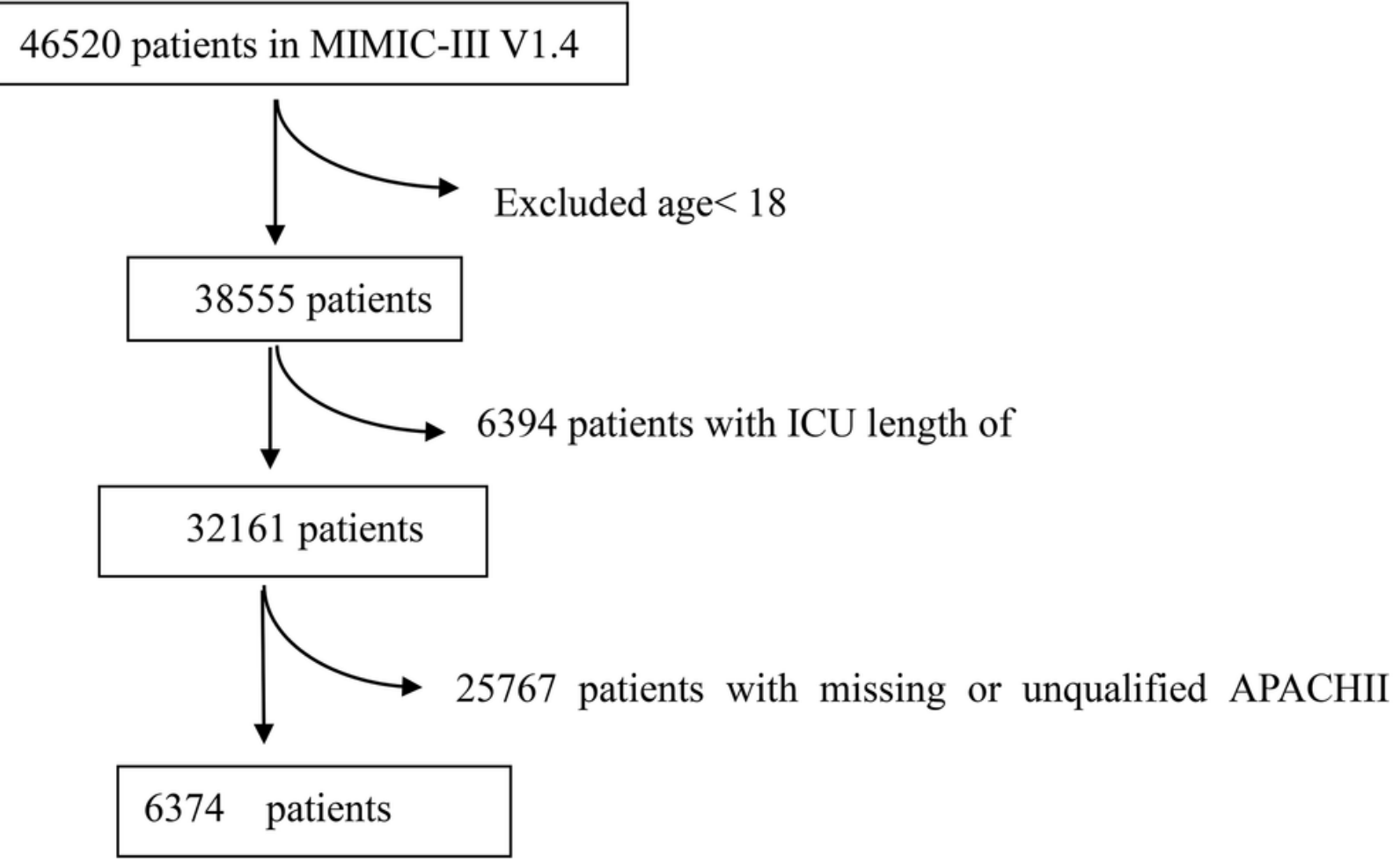

\section{Figure 1}

Flow chart. Illustration of exlusion and inclusion criteria as utilized to select the final patients. 

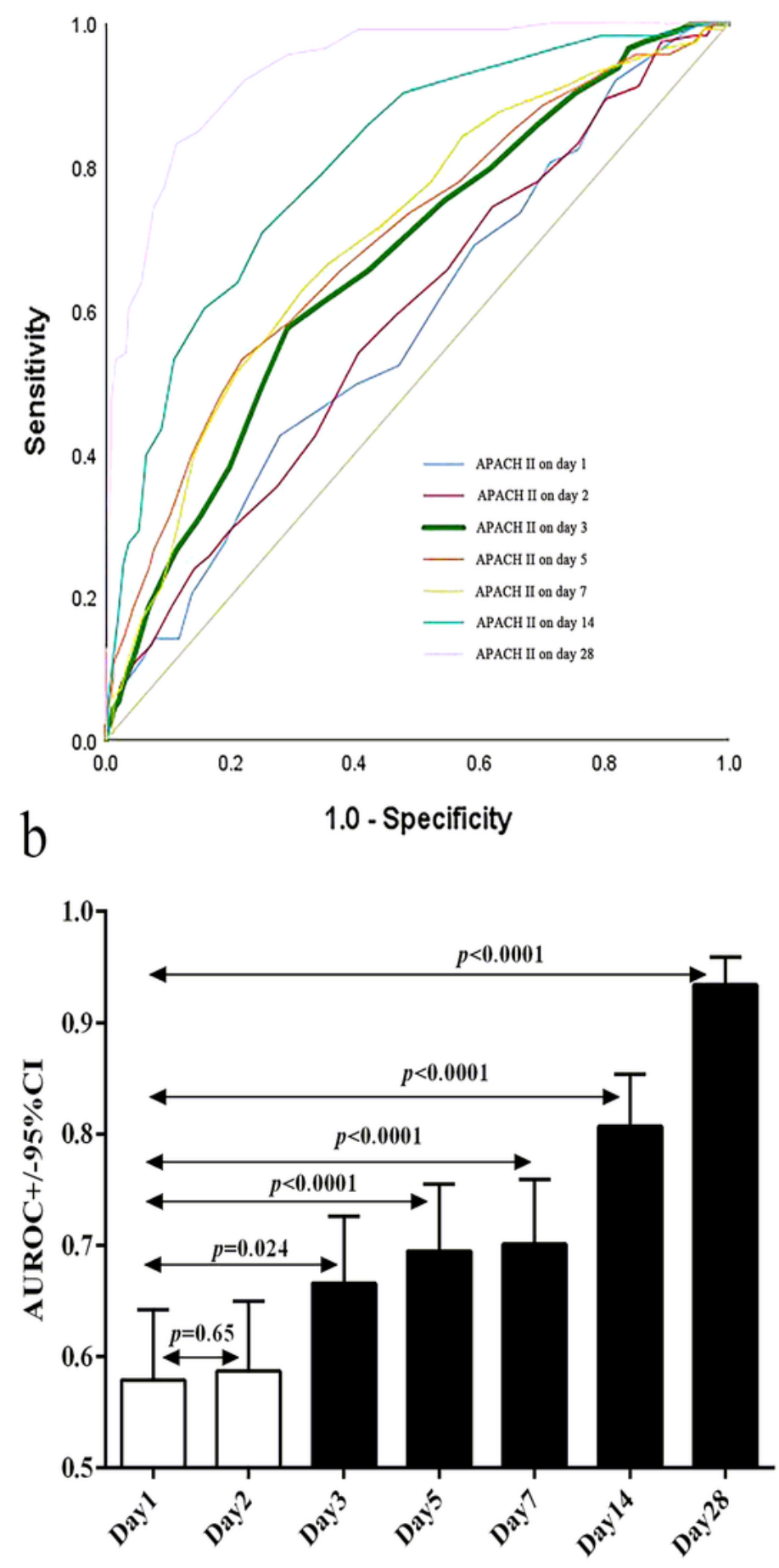

Figure 2

APACHE II on follow-up days as predictor of hospital mortality. a Receiver operating characteristic(ROC) curves for the association of series APACHE II with hospital mortality. b Comparisons of AUROCs of APACHE II . p values are provided. 


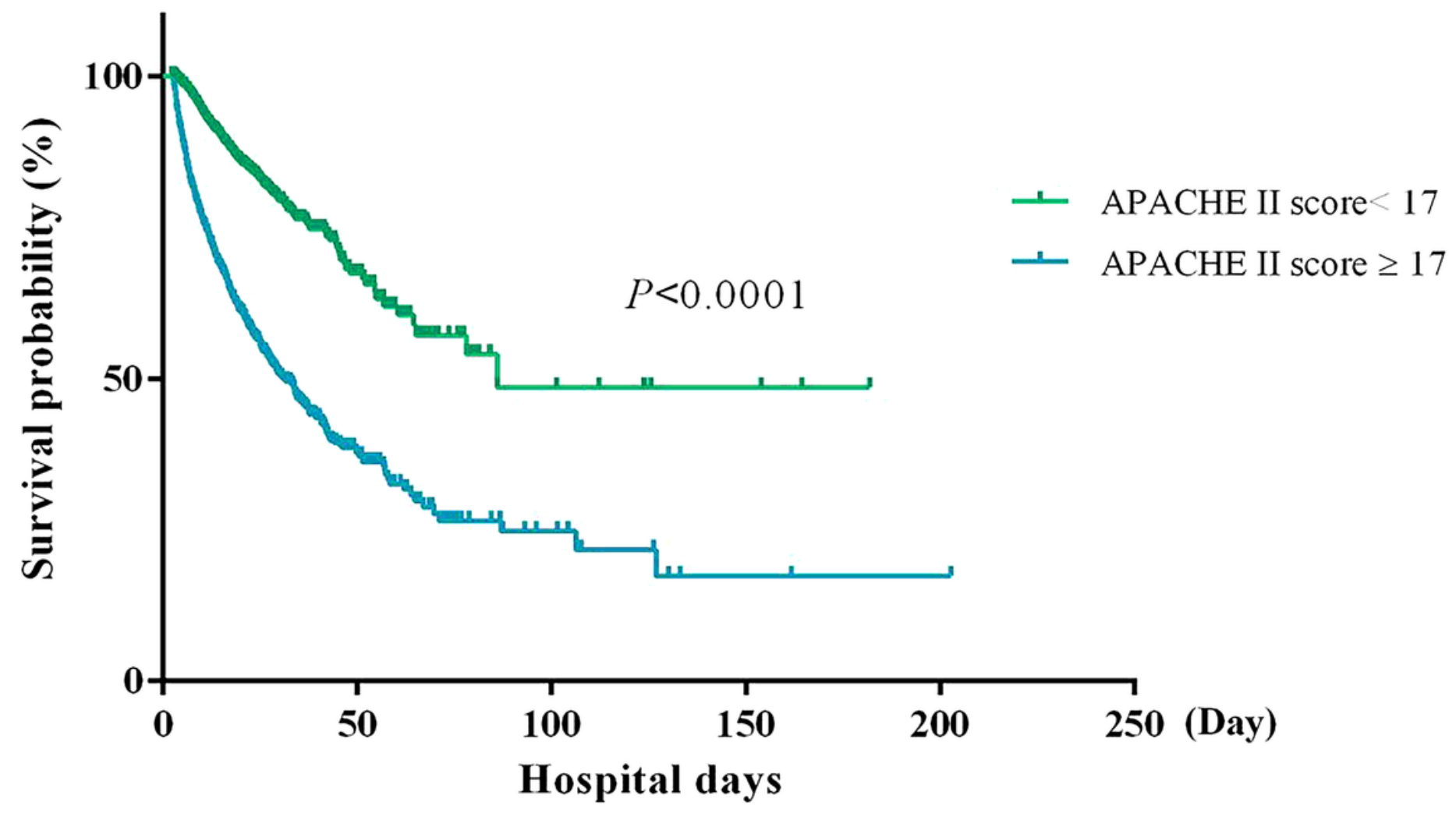

Figure 3

Survival rate in APACHE II >17 and APACHE II $₫ 17$ groups. 